\title{
IMPLEMENTASI KEADILAN RESTORATIF DALAM PENYELESAIAN PERKARA PIDANA ANAK : STUDI PADA PENGADILAN TINGGI TANJUNG KARANG
}

\author{
IMPLEMENTATION OF RESTORATIVE JUSTICE IN THE \\ SETTLEMENT OF CHILDREN CRIMINAL CASES: A STUDY AT THE \\ TANJUNG KARANG HIGH COURT
}

\author{
Fitri Setiyani Dwiarti \\ Fakultas Hukum Universitas Tulang Bawang \\ Fitrisetiyani05@gmail.com
}

\begin{abstract}
Abstrak
Penelitian ini bertujuan untuk mengetahui dan menganalisis sejauh mana implementasi keadilan restoratif (restorative justice) dalam penyelesaian perkara pidana anak di Pengadilan Tinggi Tanjung Karang dan untuk mengetahui faktor-faktor penghambat penegak hukum untuk menerapkan keadilan restoratif dalam penyelesaian perkara pidana anak di Pengadilan Tinggi Tanjung Karang. Penelitian ini merupakan penelitian hukum yuridis empiris. Berdasarkan hasil penelitian, penerapan keadilan restoratif di Pengadilan Tinggi Tanjung Karang telah dilakukan walaupun belum optimal. Penerapan keadilan restoratif terhadap anak yang berkonflik dengan hukum dalam penyelesaian perkara pidana anak di Pengadilan Tinggi Tanjung Karang masih mengalami hambatan. Hambatan tersebut antara lain pincangnya substansi Undang-Undang No. 11 Tahun 2012 tentang Sistem Peradilan Pidana Anak, durasi penanganan perkara yang singkat, dan minimnya anggaran.
\end{abstract}

Kata Kunci : Implementasi, Keadilan Restoratif, Perkara Pidana Anak

\begin{abstract}
The purpose of this research to determine and analyze the extent to which restorative justice is implemented in the settlement of juvenile criminal cases at the Tanjung Karang High Court and to determine the inhibiting factors for law enforcers to implement restorative justice in resolving juvenile criminal cases at the Tanjung Karang High Court. This research is an empirical juridical legal research. Based on the research results, the application of restorative justice at the Tanjung Karang High Court has been carried out although it is not optimal. The application of restorative justice to children in conflict with the law in resolving child criminal cases at the Tanjung Karang High Court is still experiencing obstacles. These obstacles include the limping of the substance of Law No. 11 of 2012 concerning the Juvenile Criminal Justice System, the short duration of case handling, and the minimum budget.
\end{abstract}

Keywords : Implementation, Restorative Justice, Criminal Cases for Children 


\section{A. Pendahuluan}

Anak sebagai anugerah Tuhan Yang Maha Esa sudah sepatutnya mendapat jaminan perlindungan terhadap harkat dan martbatnya. ${ }^{1}$ Anak tidak dapat dipisahkan dari keberlangusngan hidup suatu bangsa, anak merupakan generasi penerus bangsa yang harus dijamin hak-hak kemanusiaannya. ${ }^{2}$ Dewasa ini, anak acap kali menjadi sorotan di mata masyarakat karena tingkah lakunya yang bertentangan dengan norma hukum. Perilaku anak yang demikian disebut kenakalan anak (juvenile deliquency). Di Indonesia sendiri kenakalan anak masih menjadi persoalan sosial tersendiri yang menyebabkan kekhawatiran masyarakat khususnya para orangtua. $^{3}$ Bentuk kenakalan anak sangat bervariasi, seperti kejahatan kesusilaan,

1 Mashuril Anwar dan M. Ridho Wijaya, Fungsionalisasi dan Implikasi Asas Kepentingan Terbaik bagi Anak yang Berkonflik dengan Hukum: Studi Putusan Pengadilan Tinggi Tanjung Karang, Undang Jurnal Ilmu Hukum, Volume 2 No. 2, 2019, hlm. 267.

2 Rifki Septiawan Ibrahim dan Dientje Rumimpunu, Hak-Hak Keperdataan Anak dalam Perspektif Undang-Undang Nomor 35 Tahun 2014 tentang Perlindungan Anak, Lex Privatum, Volume 6 No. 2, 2018, hlm. 53.

3 Hasbi Hasan, Penerapan Keadilan Restoratif Dalam Sistem Peradilan Pidana Anak Di Indonesia, Jurnal Hukum dan Peradilan, Volume 2 No. 2, 2013, hlm. 247. penyalahgunaan narkotika, pencurian, kekerasan, penganiayaan dan sebagainya. ${ }^{4}$

Komisi Perlindungan Anak Indonesia (KPAI) menyebutkan, sepanjang tahun 2018 terdapat 1.434 kasus anak yang berhadapan dengan hukum. ${ }^{5}$ Sejak Tahun 2011 hingga Tahun 2019, KPAI menerima laporan kasus anak berhadapan dengan hukum sebanyak 11.492 kasus. Angka ini jauh lebih tinggi dibandingkan laporan kasus anak yang terjerat masalah kesehatan dan NAPZA (2.820 kasus), pornografi dan cyber crime (3.323 kasus), serta tindak pidana trafficking dan eksploitasi (2.156 kasus). ${ }^{6}$ Data Badan Peradilan Umum Mahkamah Agung menunjukan sejak tahun 2015 hingga tahun 2018, terdapat 22.730 perkara pidana khusus anak pada wilayah hukum Pengadilan Tinggi. Anak pelaku tindak pidana khususnya kekerasan masih

\footnotetext{
4 Nunung Unayah dan Muslim Sabarisman, The Phenomenon Of Juvenile Delinquency And Criminality, Sosio Informa, Volume 1 No. 2, 2015, hlm. 121.

5 Nyi R. Irmayani, "Problematika Penanganan terhadap Anak Pelaku Tindak Kekerasan Seksual Selama Menjalankan Proses Hukum: Kasus di Provinsi Kalimantan Barat", Sosio Konsepsia, Vol. 8, No. 3, (2019), hlm. 288.

6 M. Reza Sulaiman dan Risna Halidi, Anak Berhadapan Dengan Hukum Tertinggi, Potret Buram Perlindungan Anak Indonesia, Suara.com,https://www.suara.com/health/2019/07/ 23/071000/anak-berhadapan-dengan-hukum-potretburam-perlindungan-anak-di-indonesia?page $=$ all, diakses pada 27 September 2020.
} 
menjadi persoalan saat ini di Provinsi Lampung. Tahun 2019 tercatat 309 anak pelaku kekerasan di Provinsi Lampung. ${ }^{7}$ Salah satu daerah yang didaulat sebagai Kota dengan tingkat tindak pidana yang melibatkan anak yang lumayan tinggi yakni Kota Bandar Lampung. Pada tahun 2017, hasil monitoring Komisi Nasional Perlindungan Anak menunjukan bahwa Provinsi Lampung berada di peringkat 9 terkait pelaku kriminal maupun korban yang melibatkan anak. Pada tahun 2018, Lampung kembali menjadi sorotan ketika seorang anak dengan inisial $M$ yang berusia 12 tahun yang melakukan kejahatan asusila sodomi terhadap lima orang korbannya yakni MA (9), MF (6), NF (8), FA (10), dan R (11).

Fenomena diatas tentu sangat memprihatinkan, dan yang lebih disesalkan realita menunjukan sebagian besar kenakalan anak diselesaikan melalui sistem peradilan pidana dikarenakan kenakalan anak tersebut masuk dalam kategori tindak pidana berat. Berdasarkan penelusuran di Pengadilan Tinggi Tanjung Karang, perkara anak yang ditangani cukup banyak dimana terdapat 25 perkara anak. Dari 25 perkara anak tersebut,

\footnotetext{
${ }^{7}$ Kementerian Perlindungan Perempuan dan Anak, Simponi Perlindungan Perempuan dan Anak tahun 2020, (Jakarta: Kementerian Perlindungan Perempuan dan Anak, 2020).
}

sebanyak 15 perkara mengandung vonis berupa pidana penjara, 6 perkara telah berkekuatan hukum tetap. Putusan hakim tersebut tidak didasarkan pada asas ultimum remedium, seolah tidak opsi sanksi lain yang lebih berpihak pada kepentingan terbaik anak. Penyelesaian perkara anak yang demikian sangat rentan bagi masa depan anak, mengingat sistem peradilan pidana identik dengan pemidanaan dan memberikan stigma buruk terhadap anak yang dapat membahayakan kesejahteraan dan masa depan anak. ${ }^{8}$

Salah satu komitmen negara dalam memberikan perlindungan anak yakni dengan diratifikasinya konvensi hak-hak anak oleh Pemerintah dengan Keputusan Presiden Nomor 36 Tahun 1990. Pada intinya, konvensi tersebut memuat prinsipprinsip umum perlindungan anak yang meliputi non diskriminasi, kepentingan terbaik bagi anak, kelangsungan hidup dan tumbuh kembang anak, serta penghargaan atas partisipasi anak. ${ }^{9}$ Pemerintah Indonesia semakin menunjukkan keseriusannya dalam perlindungan anak dengan disahkannya Undang-Undang

\footnotetext{
8 Nyi R. Irmayani, Problematics On Handling Children Of The Perpetrators Of Sexual Violence During Legal Proceedings: Case In West Kalimantan Province, Sosio Konsepsia, Volume 8 No. 3, 2019, hlm. 299.

9 Irma Rumtianing, Kota Layak Anak Dalam Perspektif Perlindungan Anak, Jurnal Pendidikan Pancasila dan Kewarganegaraan, Volume 27 No. 1, 2014, hlm. 1.
} 
Nomor 11 tahun 2012 tentang Sistem Peradilan Pidana Anak. Sehubungan dengan berlakunya peraturan perundangundangan yang mengedepankan perlindungan terhadap anak, sistem peradilan pidana anak saat ini didasarkan pada keadilan restoratif yang bertujuan untuk memperbaiki dan memulihkan suatu keadaan akibat perbuatan kriminal yang dilakukan anak. ${ }^{10}$

Undang-Undang No. 11 Tahun 2012 tentang Sistem Peradilan Pidana Anak mengatur mekanisme penyelesaian perkara anak yang berhadapan dengan hukum dengan berlandaskan prinsip perlindungan dan kepentingan terbaik bagi anak atau yang disebut diversi yang dijiwai oleh keadilan restoratif. ${ }^{11}$ Pasal 7 UndangUndang No. 11 Tahun 2012 tentang Sistem Peradilan Pidana Anak menentukan bahwa diversi hanya dapat diterapkan terhadap tindak pidana yang ancaman pidananya dibawah tujuh tahun dan bukan pengulangan. Dianutnya prinsip keadilan restoratif dalam Undang-Undang No. 11 Tahun 2012 tentang Sistem Peradilan Pidana Anak menjadi angin segar bagi peradilan anak di Indonesia. Kendati

10 Mansyur, Mediasi Penal Terhadap Perkara KDRT, Yayasan Gema Yustisia, Jakarta, 2010.

11 Kristina Agustiani Sianturi, Perwujudan Keadilan Restoratif Dalam Sistem Peradilan Pidana Anak Melalui Diversi, Jurnal De Lega Lata, Volume 1 No. 1, 2016, hlm. 186. demikian, maraknya penyelesaian perkara anak melalui peradilan yang berujung pemidanaan terhadap anak, konsep keadilan restoratif nampaknya belum dipahami secara komprehensif ${ }^{12}$ oleh para penegak hukum sehingga penerapannya pun tampak tersendat-sendat.

Berdasarkan uraian diatas, permasalahan yang akan diteliti yakni terkait penerapan keadilan restoratif dalam penyelesaian perkara pidana anak di Pengadilan Tinggi Tanjung Karang dan faktor penghambat penerapan keadilan restoratif dalam penyelesaian perkara pidana anak di Pengadilan Tinggi Tanjung Karang.

\section{B. Metode Penelitian}

Metode yang digunakan dalam penelitian ini yakni yuridis normatif dan yuridis empiris. Pendekatan yuridis normatif yakni pendekatan yang mempelajari dan menelaah bahan pustaka dan peraturan perundang-undangan yang berkaitan dengan penelitian ini. Adapun pendekatan yuridis empiris merupakan pendekatan yang dilakukan dengan mempelajari hukum dalam kenyataan baik berupa pendapat maupun penilaian. ${ }^{13}$ Data

\footnotetext{
${ }^{12}$ Hasbi Hasan, Op Cit., hlm. 250.

13 Soerjono Soerkanto, Pengantar Penelitian Hukum. Universitas Indonesia Press, Jakarta, 1983, hlm. 41.
} 
dalam penelitian ini menggunakan data sekunder dan data primer.

\section{Pembahasan}

\section{Penerapan Keadilan Restoratif} Dalam Perkara Pidana Anak Di Pengadilan Tinggi Tanjung Karang

Anak yang berkonflik dengan hukum merupakan anak yang berumur 12 tahun dan belum berumur 18 tahun yang melakukan tindak pidana. $^{14}$ Salah satu prinsip dalam penyelesaian perkara anak yang berkonflik dengan hukum yakni keadilan restoratif. Keadilan restoratif merupakan penyelesaian perkara pidana dengan korban, pelaku, keluarga dan masyarakat, dengan tujuan untuk memulihkan keadaan dengan tidak berdasarkan pembalasan. ${ }^{15}$ Keadilan restoratif tertuang dalam Pasal 5 UndangUndang No. 11 Tahun 2012 tentang Sistem Peradilan Pidana Anak yang intinya menyatakan bahwa penyelesaian perkara pidana anak wajib mengedepankan keadilan restoratif. Hal ini dapat dilihat dari adanya ketentuan kewajiban penerapan diversi dalam penyelesaian perkara anak yang berkonflik dengan

${ }^{14}$ Febriana Annisa, Penegakkan Hukum Terhadap Anak Yang Melakukan Tindak Pidana Pencabulan Dalam Konsep Restorative Justice, ADIL: Jurnal Ilmu Hukum, Volume 7 No. 2, 2016, hlm. 205.

${ }^{15}$ Hasbi Hasan, Op Cit., hlm. 260. hukum. Berdasarkan penelusuran di Pengadilan Tinggi Tanjung Karang, perkara anak yang ditangani cukup banyak dimana terdapat 25 perkara anak. Dari 25 perkara anak tersebut, sebanyak 15 perkara mengandung vonis berupa pidana penjara, 6 perkara telah berkekuatan hukum tetap.

Tabel 1. Keadaan Perkara Pidana Anak Pada Seluruh Pengadilan Negeri Di Provinsi Lampung $2019^{16}$

\begin{tabular}{|c|c|c|c|c|c|}
\hline \multirow[b]{2}{*}{$\begin{array}{l}\mathbf{N} \\
\mathbf{0}\end{array}$} & \multirow[b]{2}{*}{$\begin{array}{l}\text { Pengadil } \\
\text { an Negeri }\end{array}$} & \multicolumn{2}{|c|}{ Putusan } & \multirow{2}{*}{$\begin{array}{c}\text { Pidan } \\
\text { a dan } \\
\text { Tinda } \\
\text { kan }\end{array}$} & \multirow[b]{2}{*}{$\begin{array}{c}\text { Perio } \\
\text { de }\end{array}$} \\
\hline & & $\begin{array}{c}\text { Pid } \\
\text { an } \\
\mathbf{a}\end{array}$ & $\begin{array}{l}\text { Tin } \\
\text { dak } \\
\text { an }\end{array}$ & & \\
\hline 1 & $\begin{array}{l}\text { Tanjung } \\
\text { Karang }\end{array}$ & 403 & 21 & 1 & $\begin{array}{l}2015- \\
\text { Nove } \\
\text { mber } \\
2020\end{array}$ \\
\hline 2 & Metro & 49 & 17 & 1 & $\begin{array}{l}2015- \\
\text { Septe } \\
\text { mber } \\
2020\end{array}$ \\
\hline 3 & Kotabumi & 108 & 17 & 2 & $\begin{array}{c}2015- \\
\text { Oktob } \\
\text { er } \\
2020\end{array}$ \\
\hline 4 & Kalianda & 183 & 9 & 1 & $\begin{array}{c}2015- \\
\text { Oktob } \\
\text { er } \\
2020\end{array}$ \\
\hline 5 & Liwa & 41 & 0 & 0 & $\begin{array}{c}2015- \\
\text { Oktob } \\
\text { er } \\
2020\end{array}$ \\
\hline 6 & Menggala & 126 & 2 & 1 & $\begin{array}{c}2015- \\
\text { Oktob } \\
\text { er } \\
2020\end{array}$ \\
\hline 7 & $\begin{array}{l}\text { Gunung } \\
\text { Sugih }\end{array}$ & 161 & 13 & 1 & $\begin{array}{c}2015- \\
\text { Oktob } \\
\text { er } \\
2020\end{array}$ \\
\hline 8 & Sukadana & 217 & 8 & 1 & 2015- \\
\hline
\end{tabular}

${ }^{16}$ Mashuril Anwar, Reformulasi Sanksi Tindakan Bersifat Primum Remedium Terhadap Anak Berkonflik Dengan Hukum, Tesis, Fakultas Hukum Universitas Lampung, 2020. 


\begin{tabular}{|c|c|c|c|c|c|}
\hline & & & & & $\begin{array}{l}\text { Nove } \\
\text { mber } \\
2020\end{array}$ \\
\hline 9 & $\begin{array}{l}\text { Blambang } \\
\text { an Umpu }\end{array}$ & 106 & 2 & 0 & $\begin{array}{l}2015- \\
\text { Nove } \\
\text { mber } \\
2020\end{array}$ \\
\hline $\begin{array}{l}1 \\
0\end{array}$ & $\begin{array}{l}\text { Kota } \\
\text { Agung }\end{array}$ & 156 & 4 & 2 & $\begin{array}{l}2015- \\
\text { Nove } \\
\text { mber } \\
2020\end{array}$ \\
\hline $\begin{array}{l}1 \\
1\end{array}$ & $\begin{array}{l}\text { Gedong } \\
\text { Tataan }\end{array}$ & 47 & 0 & 0 & $\begin{array}{c}2018- \\
\text { Oktob } \\
\text { er } \\
2020\end{array}$ \\
\hline & TOTAL & $\begin{array}{l}1.5 \\
97\end{array}$ & 93 & 10 & \\
\hline
\end{tabular}

Menurut Salman, anak adalah bagian warga negara yang harus dilindungi karena mereka merupakan generasi bangsa yang dimasa yang akan datang akan melanjutkan kepemimpinan bangsa. Upaya yang dapat dilakukan agar penerapan keadilan restoratif dapat berjalan optimal dan proporsional, diperlukan pendekatan oleh BAPAS, orangtua, dan penyidik karena anak perlu mendapatkan pendidikan formal seperti sekolah. ${ }^{17}$ Lebih lanjut Salman menjelaskan bahwa selama bertugas telah menangani perkara anak yang berkonflik dengan hukum, 4 diantaranya telah diterapkan keadilan restoratif.

Menurut Lilik Septriyana, untuk optimalisasi penerapan keadilan restoratif

\footnotetext{
17 Berdasarkan hasil wawancara dengan Salman selaku Hakim pada Pengadilan Negeri Tanjung Karang.
}

terhadap anak yang berkonflik dengan hukum harus ada keseimbangan dalam artian persamaan pandangan antara BAPAS, Penyidik, Jaksa, dan Hakim. Selama bertugas, telah menangani 13 perkara anak yang berkonflik dengan hukum 9 diantaranya diterapkan keadilan restoratif yakni diversi. ${ }^{18}$ Adapun menurut Hendra agar penerapan keadilan restoratif dapat optimal dan proporsional diperlukan komunikasi yang baik antara orangtua, Hakim, Jaksa, Penyidik, dan Polri sehingga anak memperoleh keadilan dan tidak menjadi lebih brutal. Selama bertugas, sudah menangani 20 perkara anak yang berkonflik dengan hukum dan 12 perkara diterapkan keadilan restoratif. ${ }^{19}$

Berdasarkan uraian diatas dapat dipahami bahwa penerapan keadilan restoratif di wilayah hukum Pengadilan Tinggi Tanjung Karang telah dilakukan walaupun belum sepenuhnya. Hal ini mengingat tidak semua perkara anak yang berkonflik dengan hukum dapat diterapkan keadilan restoratif. Terhadap tindak pidana yang masuk kategori berat misalnya ancaman hukumannya diatas tujuh tahun dan merupakan pengulangan tindak pidana

\footnotetext{
18 Berdasarkan hasil wawancara dengan Lilik Septriyana selaku Kasi Perdata dan TUN Kejaksaan Negeri Pringsewu.

19 Berdasarkan hasil wawancara dengan Hendra selaku anggota Kepolisian Resort Lampung Tengah.
} 
tidak dapat diberikan keadilan restoratif yang menjiwai diversi. Terlepas dari itu, keadilan restoratif juga bergantung pada diskresi aparat penegak hukum. ${ }^{20}$ Walaupun tindak pidana yang dilakukan masuk kategori tindak pidana berat, namun apabila anak tersebut masih berusia dibawah 12 tahun maka dapat dikenakan sanksi tindakan berupa pengembalian kepada orangtua, kewajiban mengikuti pendidikan dan sebagainya.

Upaya yang harus dilakukan agar penerapan keadilan restoratif terlaksana secara optimal diantaranya :

a. Membentuk regulasi yang mengedepankan keadilan restoratif;

b. Melakukan sosialisasi mengenai keadilan restoratif kepada penegak hukum dan masyarakat;

c. Meningkatkan koordinasi antar lembaga penegak hukum;

d. Meningkatkan peranan masyarakat dalam penerapan keadilan restoratif.

\section{Faktor Penghambat Penerapan Keadilan Restoratif Dalam Penyelesaian Perkara Pidana Anak Di Pengadilan Tinggi Tanjung Karang}

20 Priyo Santoso, Diskresi Kepolisian Melalui Mediasi Penal (Studi Kasus di Polsek Galur, Kulonprogo), Jurnal Penegakan Hukum dan Keadilan, Volume 1 No. 2, 2020, hlm. 98.
Sistem peradilan pidana anak saat ini belum sepenuhnya mencerminkan keadilan restoratif yang seutuhnya. Penerapan keadilan restoratif dalam Undang-Undang No. 11 Tahun 2012 tentang Sistem Peradilan Pidana Anak cenderung kepada diversi. Undang-Undang No. 11 Tahun 2012 tentang Sistem Peradilan Pidana Anak hanya memahami keadilan restoratif sebagai upaya penyelesaian perkara anak diluar proses peradilan. Kondisi diatas menggambarkan bahwa substansi UndangUndang No. 11 Tahun 2012 tentang Sistem Peradilan Pidana Anak masih pincang. Sehingga tidak heran dalam pelaksanaan keadilan restoratif sering mengalami kendala.

Setidaknya ada empat fakta yang menandai gagalnya penegakan hukum, yakni ketidakmandirian hukum, buruknya integritas penegak hukum, kondisi masyarakat yang rapuh, dan pertumbuhan hukum tidak dinamis. ${ }^{21}$ Menurut Lilik Septriyana, substansi Undang-Undang No. 11 Tahun 2012 tentang Sistem Peradilan Pidana Anak belum komprehensif mengatur mekanisme koordinasi antara para penegak hukum (Polisi, Jaksa, Hakim, dam BAPAS) dalam penerapan keadilan restoratif terhadap anak yang

21 Faisal, Menerobos Positivisme Hukum, Mata Padi Presindo, Jakarta, 2010, hlm. 81. 
berkonflik dengan hukum. selain itu, Undang-Undang No. 11 Tahun 2012 belum memuat sanksi apabila koordinasi antar penegak hukum tidak dilaksanakan. ${ }^{22}$ Hambatan penerapan keadilan restoratif terhadap anak yang berkonflik dengan hukum disebabkan durasi yang minim. Lilik Septriyana menyatakan bahwa waktu penanganan perkara anak sangat pendek, sehingga seringkali tergesah-gesah dalam penanganan perkaranya karena berpacu dengan waktu. Disamping itu, minimnya anggaran juga berpengaruh pada penerapan keadilan restoratif terhadap anak pelaku kriminal ${ }^{23}$

Berdasarkan uraian diatas, penerapan keadilan restoratif terhadap anak yang berkonflik dengan hukum dalam sistem peradilan pidana anak di Kota Bandar Lampung masih mengalami hambatan. Hambatan tersebut antara lain pincangnya substansi Undang-Undang No. 11 Tahun 2012, durasi penanganan perkara yang singkat, dan minimnya anggaran. Dengan demikian menurut Penulis, perlu dilakukan langkah-langkah konkret untuk menanggulangi hambatan-hambatan dalam penerapan keadilan restoratif terhadap

\footnotetext{
22 Berdasarkan hasil wawancara dengan Lilik Septriyana selaku Kasi Perdata dan TUN Kejaksaan Negeri Pringsewu.

23 Berdasarkan hasil wawancara dengan Lilik Septriyana selaku Kasi Perdata dan TUN Kejaksaan Negeri Pringsewu.
}

anak yang berkonflik dengan hukum di Kota Bandar Lampung. selain itu, perlu adanya peralihan paradigma dalam penanganan perkara anak yang berkonflik dengan hukum. Selama ini penegak hukum cenderung kepada paham positivisme, sehingga hanya fokus pada aturan tertulis saja.

\section{Kesimpulan}

Berdasarkan uraian diatas dapat disimpulkan bahwa penerapan keadilan restoratif dalam penyelesaian perkara pidana anak di Pengadilan Tinggi Tanjung Karang telah dilakukan walaupun belum dapat dikatakan optimal. Dikatakan demikian karena tidak semua perkara anak yang berkonflik dengan hukum dapat diterapkan keadilan restoratif. Terhadap tindak pidana yang masuk kategori berat misalnya ancaman hukumannya diatas tujuh tahun dan merupakan pengulangan tindak pidana tidak dapat diberikan keadilan restoratif yang menjiwai diversi. Terlepas dari itu, keadilan restoratif juga bergantung pada diskresi aparat penegak hukum. Penerapan keadilan restoratif terhadap anak yang berkonflik dengan hukum dalam sistem peradilan pidana anak di Kota Bandar Lampung masih mengalami hambatan. Hambatan tersebut antara lain pincangnya substansi UndangUndang No. 11 Tahun 2012, durasi 
penanganan perkara yang singkat, dan minimnya anggaran. Dalam hal mengantisipasi hambatan tersebut diperlukan peningkatan kualitas sumber daya manusia di lembaga penegak hukum, serta penerapan keadilan restoratif harus diawasi untuk menjamin hak, keadilan dan kepastian hukum bagi anak yang erkonflik dengan hukum.

\section{Daftar Pustaka}

\section{Buku}

Faisal, Menerobos Positivisme Hukum. Jakarta : Mata Padi Presindo, 2010.

Kementerian Perlindungan Perempuan dan Anak, Simponi Perlindungan Perempuan dan Anak tahun 2020, (Jakarta: Kementerian Perlindungan Perempuan dan Anak, 2020).

Mansyur, Mediasi Penal Terhadap Perkara KDRT, Jakarta : Yayasan Gema Yustisia, 2010.

\section{Karya Ilmiah}

Agustiani Sianturi, Kristina. Perwujudan Keadilan Restoratif Dalam Sistem Peradilan Pidana Anak Melalui Diversi. Jurnal De Lega Lata, Volume 1, No. 1, 2016.

Annisa, Febriana. Penegakkan Hukum Terhadap Anak Yang Melakukan Tindak Pidana Pencabulan Dalam Konsep Restorative Justice. ADIL: Jurnal Ilmu Hukum, Volume 7 No. 2, 2016.
Anwar, Mashuril dan M. Ridho Wijaya. Fungsionalisasi dan Implikasi Asas Kepentingan Terbaik bagi Anak yang Berkonflik dengan Hukum: Studi Putusan Pengadilan Tinggi Tanjung Karang. Undang Jurnal Ilmu Hukum, Volume 2 No. 2, 2019.

-------, Reformulasi Sanksi Tindakan Bersifat Primum Remedium Terhadap Anak Berkonflik Dengan Hukum, Tesis, Fakultas Hukum Universitas Lampung, 2020.

Hasan, Hasbi. Penerapan Keadilan Restoratif Dalam Sistem Peradilan Pidana Anak Di Indonesia. Jurnal Hukum dan Peradilan, Volume 2 No. 2, 2013.

Ibrahim, Rifki Septiawan dan Dientje Rumimpunu. Hak-Hak Keperdataan Anak dalam Perspektif UndangUndang Nomor 35 Tahun 2014 tentang Perlindungan Anak. Lex Privatum, Volume 6 No. 2, 2018.

Irmayani, Nyi R. Problematics On Handling Children Of The Perpetrators Of Sexual Violence During Legal Proceedings: Case In West Kalimantan Province. Sosio Konsepsia, Volume 8 No.3, 2019.

Rumtianing, Irma. Kota Layak Anak Dalam Perspektif Perlindungan Anak. Jurnal Pendidikan Pancasila dan Kewarganegaraan. Volume 27 No. 1, 2014.

Unayah, Nunung dan Muslim Sabarisman.

The Phenomenon Of Juvenile Delinquency And Criminality. Sosio Informa, Volume 1 No. 2, 2015. 


\section{Website}

Sulaiman, M. Reza dan Risna Halidi, Anak Berhadapan Dengan Hukum Tertinggi, Potret Buram Perlindungan Anak Indonesia, Suara.com,https://www.suara.com/hea lth/2019/07/23/071000/anakberhadapan-dengan-hukum-potretburam-perlindungan-anak-diindonesia?page $=$ all. diakses pada 27 September 2020 pukul 19.15 WIB

\section{Peraturan Perundang - Undangan}

Undang-Undang Dasar Republik Indonesia Tahun 1945

Undang-Undang No. 11 Tahun 2012 tentang Sistem Peradilan Pidana Anak 